\title{
Bağ toprağına uygulanan organik materyallerin verim, kalite ve besin elementleri alımına etkisi
}

\section{Effects of organic materials applied to vineyard soil on yield, quality and nutrition}

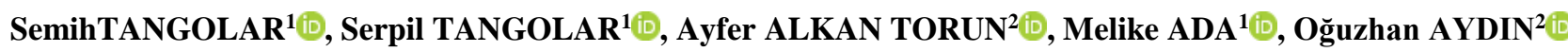 \\ ${ }^{1}$ Cukurova Üniversitesi, Ziraat Fakültesi, Bahçe Bitkileri Bölümü, Adana \\ ${ }^{2}$ Çukurova Üniversitesi, Ziraat Fakültesi, Toprak Bilimi ve Bitki Besleme Bölümü, Adana \\ Sorumlu yazar (Corresponding author): S. Tongalar, e-posta (e-mail): stangolar@cu.edu.tr \\ Yazar(lar) e-posta (Authore-mail): tangolar@cu.edu.tr, atorun@cu.edu.tr,melikeada46@gmail.com,oguzhanaydiin@gmail.com
}

\section{MAKALE BİLGİSI}

Alınış tarihi 12 Mart 2019

Düzeltilme tarihi 19 Nisan 2019

Kabul tarihi 26 Nisan 2019

\section{Anahtar Kelimeler:}

Asma

Kompost

Makro ve mikro element

Pomza

\section{ÖZ}

Bu çalışmada, bağ toprağına farklı organik materyal uygulamalarının (Kontrol (K), Bazaltik Pomza (P), Kuru kompost (KK), Budama odunu artığ $1+$ çiftlik gübresi kompostu (BA+ÇG), Saman+Çiftlik gübresi kompostu $(\mathrm{S}+\mathrm{C} G)$, Bazaltik Pomza+Kuru kompost $(\mathrm{P}+\mathrm{KK})$, Bazaltik Pomza+Saman+Çiftlik gübresi kompostu $(\mathrm{P}+\mathrm{S}+\mathrm{C} G)$ ve Bazaltik Pomza+Budama odunu artığ $1+$ Çiftlik gübresi kompostu (P+BA+ÇG)) Çukurova koșullarında yetiștirilen Early Sweet çeşidinin üzüm verimi ile salkım, tane ve şıra özellikleri yanında yaprak makro ve mikro element düzeyleri üzerine etkileri araștırılmıștır. Sonuçta; çalıșmanın birinci yılında verim ve salkım ağırlığında en iyi sonuç S+ÇG uygulamasından (sırasıyla $4474 \mathrm{~g} \mathrm{omca}^{-1}-2980 \mathrm{~kg} \mathrm{da}^{-1}$ ve $447.4 \mathrm{~g}$ ); ikinci yılda ise Pomza (sırasıly $3799 \mathrm{~g} \mathrm{omca}^{-1}-2530 \mathrm{~kg} \mathrm{da}^{-1}$ ve $422.1 \mathrm{~g}$ ) uygulamasından elde edilmiștir. En düșük verim ve salkım ağırlığı değerleri çalıșmanın birinci yılında kontrol; ikinci yılında ise aynı istatistiki grupta yer alan Kontrol, KK ve BA+ÇG uygulamalarından alınmıştır. Birinci yıl $\mathrm{BA}+\mathrm{ÇG}$; ikinci yıl $\mathrm{S}+\mathrm{C} G, \mathrm{P}+\mathrm{KK}, \mathrm{P}+\mathrm{S}+\mathrm{C} G$ ve $\mathrm{P}+\mathrm{BA}+\mathrm{C} G$ uygulamalarında yaprak azot düzeyi daha yüksek çıkmıștır. İki deneme yılında da en yüksek fosfor ve potasyum değerleri Pomza uygulamasından elde edilmiştir. Her iki yılda da en yüksek demir düzeyi $\mathrm{P}+\mathrm{S}+\mathrm{CG}$ uygulamasında, mangan konsantrasyonu ise $\mathrm{P}+\mathrm{BA}+\mathrm{CG}$ uygulamasında saptanmıştır. Bütün uygulamalarda azot, fosfor, kalsiyum, demir ve mangan konsantrasyonunun yeterli, potasyum, magnezyum ve çinko değerlerinin ise noksanlık sınırlar içerisinde yer aldığı belirlenmiștir. Organik materyal uygulamalarının, incelenen özellikler açısından kontrole göre genel olarak bir miktar iyileşme sağladığı saptanmıştır. Uygun materyal önerisi için, uygulamaların sürdürülerek materyallerin biriken etkisinin gözlenmesinde yarar görülmektedir.

\section{ARTICLE INFO}

Received 12 March 2019

Received in revised form 19 April 2019

Accepted 26 April 2019

\section{Keywords:}

Grapevine

Compost

Macro and micro element

Pumice

\begin{abstract}
In this study, the effects of different organic material applications (Control $(\mathrm{K})$, Basaltic pumice $(\mathrm{P})$, Dry compost $(\mathrm{KK})$, Pruning wood residue + Farm manure compost $(\mathrm{BA}+\mathrm{CG})$, Straw + Farm manure compost $(\mathrm{S}+\mathrm{CG})$, Basaltic pumice + Dry compost $(\mathrm{P}+\mathrm{KK})$, Basaltic pumice + Straw + Farm manure compost $(\mathrm{P}+$ $\mathrm{S}+\mathrm{CG})$ and Basaltic pumice + Pruning wood residue + Farm manure compost $(\mathrm{P}+\mathrm{BA}+\mathrm{CG})$ on grape yield, cluster, berry and must characteristics and leaf macro and micro element levels of Early Sweet varieties were investigated. According to the data, in terms of yield and cluster weight, the best results, in the first year of the study from S + CG application (4474 $\mathrm{g}$ vine $^{-1}-2980 \mathrm{~kg} \mathrm{da}^{-1}$ and $447.4 \mathrm{~g}$ respectively) and in the second year from Pumice $\left(3799 \mathrm{~g} \mathrm{omca}^{-1}-2530 \mathrm{~kg} \mathrm{da}^{-1}\right.$ and $422.1 \mathrm{~g}$ respectively) were obtained The lowest yield and cluster weight values were obtained in the first year of study from Control; In the second year from Control, KK and BA + CG applications that were included in the same statistical group. In the first year BA + CG; in the second year S + CG; P + KK; P + S + CG and P + BA + CG applications resulted in higher leaf nitrogen level. In the two experimental years, the highest phosphorus and potassium values were obtained from the pumice application. In both years, the highest iron level was found in $\mathrm{P}+\mathrm{S}+$ CG applications and manganese concentration was determined in P + BA + CG application. Nitrogen, phosphorus, calcium, iron and manganese concentrations were found to be sufficient in all applications, while potassium, magnesium and zinc values were within the limits of deficiency. It has been determined that organic material applications generally provide some improvement in terms of the properties examined. For the appropriate material recommendation, it is beneficial to observe the accumulated effect of the materials by continuing the applications.
\end{abstract}




\section{Giriş}

Akdeniz iklimi etkisi altındaki toprakların çoğunda, organik karbon içeriği düşüktür (\%0.5-1.0 organik karbon) ve iklimsel koşullar toprakta organik madde birikimi için uygun değildir. Düşük organik madde içeriği yalnızca bitki gelişimini değil, aynı zamanda doğal mikrobiyal populasyonların gelişimini de etkilemektedir (Rodeghiero ve ark. 2011). Bundan dolayı toprakta organik madde düzeyini artıracak uygulamaların yapılması, üzerinde durulması gereken öncelikli konulardan birisidir.

Kompost, tarımda ve bahçe bitkilerinde geniş alanlarda ve son yıllarda bağcılıkta da kullanılan önemli bir materyaldir (Pinamonti 1998; Korboulewsky ve ark. 2004; Powell ve ark. 2007). Kompostun genel faydaları içinde; toprağın su tutma kapasitesini geliştirmek (Aggelides ve Londra 2000; Curtis ve Claassen 2005; Mylavarapu ve Zinati 2009), organik madde ve bitki besin maddelerini sağlamak, ilaveten toprağın fiziksel özelliklerini geliştirmek, toprağın toplam porozite (Jamroz ve Drozd 1999; Aggelides ve Londra 2000), agregat oluşumu (Çelik ve ark. 2005; Sodhi ve ark. 2009) ve hidrolik iletkenliğini arttırmak (Curtis ve Claassen 2009) önemli yer tutmaktadır.

Esas itibariyle yabancı otları kontrol altında tutmak amacıyla yapılan malçlama işlemi, aynı zamanda toprak sıcaklığının düzenlenmesine, erozyonun kontrolüne, toprak yüzeyinden olabilecek buharlaşmanın azaltılmasına da yardımcı olmakta böylece topraktan besin maddesi alımı ve mikroorganizma faaliyetlerini iyileştirmektedir. Ağaç kabukları ve yaprakları, sap, saman, ot, parçalanmış mısır sapları, budama atıkları, posa, kompost ve çiftlik gübreleri organik malçlar olarak bilinmektedir. Buna karşıllı taş, kum, çakıl, kül, toz, volkanik tüf vb. malç olarak kullanılan inorganik materyallerdir. Kağıt, plastik naylon, tekstil ürünleri, plastik köpük, alüminyum levhalar vb. sentetik malçlardır.

Asmanın her y1l düzenli ürün verebilmesi için üzüm, budama artıkları ve yıkanma yoluyla topraktan kaybolan besin maddesi miktarlarının toprağa geri kazandırılması gerekmektedir. Yapılan araştırmalar, asmanın 1 ton ürün ile topraktan her yıl budama artıkları da dahil olmak üzere dekardan yaklaşık $12 \mathrm{~kg} \mathrm{~N}, 4 \mathrm{~kg} \mathrm{P}_{2} \mathrm{O}_{5}$ ve $14 \mathrm{~kg} \mathrm{~K} 20$ ve diğer besin elementlerini de belli oranlarda kaldırdığını göstermiştir. Bunların ve eksilen diğer maddelerin toprağa, doğrudan mineral gübreleme ile veya doğal yollar ile, yani doğal minerallerin, organik gübrelerin, yeşil gübre bitkilerinin ve biyolojik yöntemlerin kullanılması yoluyla kazandırılması önerilmektedir (Anaç ve ark. 2002).

Çiftlik gübresi yanında, budama artıkları ve çiftlik gübresi karışımından elde edilen kompost ve doğal mineralleri içeren pomza, malç etkisi yanında asmanın beslenmesinde de kullanılabilecek doğal materyaller olarak önem taşımaktadır. Böyle materyallerin kullanılması suretiyle, organik gübreleme yoluyla, erozyonun önlenmesinin ve toprağın fiziksel, kimyasal ve biyolojik özelliklerinin muhafazasının mümkün olabileceği belirtilmiştir (Altieri 1987; Lampkin 1990).

Çiftlik gübreleri ile yapılan gübreleme, toprağın besin maddesi kapasitesini artırma yanında, kimyasal, fiziksel ve biyolojik özelliklerini iyileştirdiğinden, geleneksel bağcllıkta da çok önerilen uygulamalar arasında yer almaktadır (Winkler ve ark. 1974; Weaver 1976; Bhangoo ve ark. 1988; Çelik ve ark. 1998).
Dünyada olduğu gibi Ülkemizde de ekonomik zorluklardan veya çevreye olumsuz etkilerinden dolayı toprak verimliliğini muhafaza etmek veya arttırmak amacıyla kimyasal gübrelerin kullanılmasına karşı nispeten bir çekingenliğin varlığ hissedilmektedir. $\mathrm{Bu}$ nedenle üreticilerimize alternatif, daha ucuz ve etkin bitki besin elementleri kaynaklarının bulunmas1 ve önerilmesinin önemli hedefler arasında yer alması gerektiği düşünülmüştür.

Çiftlik gübreleri ile asmanın budama artıkları karışımından oluşan kompost bu ihtiyaca cevap verebilecek bir özellik taşımaktadır. Kırsal alanda yürütülen hayvancılık faaliyetleri kapsamında elde edilen gübrelerin etkinliğinin kompost oluşturulması yoluyla artırılarak kullanılması ekonomiye katk1 getirebilecek bir faaliyet olarak görülmektedir. Budama artıklarının bu şekilde kullanılması bağların beslenmesine artı değer katabilecektir.

$\mathrm{Bu}$ araştırmanın amacı, asma büyümesi ve verimliliği ile bitki beslenmesi üzerine saman ile asma budama artığı ve çiftlik gübresi karışımından elde edilen kompostlar yanında ticari kuru kompostun ve pomza (bazaltik tüf) uygulamasının etkisini belirlemektir. Böylece kimyasal gübre kullanımının azaltılması ulaşılması hedeflenen amaçlar arasında yer almaktadır.

\section{Materyal ve Yöntem}

Araştırma, Çukurova Üniversitesi Ziraat Fakültesi Bahçe Bitkileri Bölümü Araştırma ve Uygulama Bağında 2017-2018 yıllarında iki yıl süreyle yürütülmüştür. Adana'da $36^{\circ} 59^{\prime} \mathrm{N}$ enlemi ve $35^{\circ} 18^{\prime}$ E boylamında yer alan deneme alanının denizden ortalama yüksekliği 40 m'dir. Araştırma materyalini 1103 Paulsen anacı üzerine aşılı Early Sweet çeşidinin sıra arası 1.5 sıra üzeri $1 \mathrm{~m}$ arayla, kuzey-güney yönünde tesis edilmiş 4 yaşındaki asmaları oluşturmaktadır.

Deneme kapsamında etkisi denenen uygulamalar,

A) Asma budama artığı:Çiftlik gübresi karışımı kompost (1:2, v:v) $\left(5\right.$ ton $\left.\mathrm{da}^{-1}\right)$,

B) Saman:Çiftlik gübresi karışımı kompost (v:v) (5 ton da $\left.\mathrm{da}^{-1}\right)$,

C) Ticari kompost $\left(400 \mathrm{~kg} \mathrm{da}^{-1}\right)$

D) Pomza (bazaltik tüf) $\left(5\right.$ ton $\left.\mathrm{da}^{-1}\right)$

E) A+D karışımı,

F) B+D karışımı,

G) C+D karışımı ve

H) Kontrol (hiç bir uygulama yok) olmak üzere 8 uygulama yapılmıştır.

$\mathrm{Bu}$ denemede kullanılan budama artıkları, Ç.Ü. Ziraat Fakültesi Bahçe Bitkileri Bölümü Araştırma Bağından, saman ve çiftlik gübresi Ziraat Fakültesi Döner Sermaye çiftlik müdürlügünden, bazaltik pomza ise Adana-Osmaniye illeri arasında Delihalil ve Üçtepeler'de bulunan pomza yataklarından temin edilmiştir.

Uygulama materyallerinin toprağa dağıtılması birinci y1l şubat ayında, ikinci yıl ocak ayında yapılııs ve ardından 15-20 $\mathrm{cm}$ derinlikte toprağa karışması bir el rotovatörüyle gerçekleştirilmiştir. Bir beyaz kuşnet ile örtülen deneme alanında tüm parseller damla sulama yöntemi ile sulanmıştır.

Çalışmada üzüm verimi $\left(\mathrm{g} \mathrm{omca}^{-1}\right)$, salkım ağırlığı $(\mathrm{g})$, tane ağırlığ ${ }^{(\mathrm{g})}$, tane hacmi (ml), Suda Çözünebilir Kuru Madde Miktarı (SÇKM) (\%), asitlik (\%), pH ve olgunluk indisine bakılmıştır. 


\subsection{Yaprak Örneklerinin Alınması ve Analizi}

Uygulamaların yaprakların besin maddeleri düzeyi üzerine etkisinin saptanması amaciyla tam çiçeklenme döneminde salkımın karşısındaki yapraklar örnek olarak alınmıştır (Winkler ve ark. 1974; Weaver 1976; Ecevit 1980 ve 1986; Bhangoo ve ark. 1988; Tangolar ve Ergenoğlu 1989; Pool ve ark. 1990; Yılmaz 1993; Porro ve ark. 1996; Bayraklı ve Er 1998; Çelik ve ark. 1998). Yaprak örnekleri, her uygulama ve yinelemeden alınmıştır.

Yaprak örnekleri, Ç.Ü. Ziraat Fakültesi Bitki Besleme ve Toprak bölümünün bitki besleme laboratuvarında Kaçar (1972)'a göre, önce yıkanıp sonra da etüvde $60-65^{\circ} \mathrm{C}$ de 48 saat kurutma ve öğütme işlemlerine tabii tutularak analize hazır duruma getirilmiştir. Bitki örneklerindeki azot dışındaki diğer elementlerin tamamında kuru yakma yöntemi kullanılmıştır.

Bitki örneklerinde yüzde toplam $\mathrm{N}$, Kjeldahl; $\mathrm{P}$ spektrofotometre ile $\mathrm{K}, \mathrm{Ca}, \mathrm{Mg}, \mathrm{Fe}, \mathrm{Mn}$ ve $\mathrm{Zn}$ analizi Atomik Absorbsiyon Spektrofotometre kullanılarak yapılmış, makro elementler \%; mikro elementler ise $\mathrm{mg} \mathrm{kg}^{-1}$ (ppm) olarak verilmiştir (Kacar 1995).

\subsection{Deneme Deseni ve Istatistik Analiz}

Deneme 3 yinelemeli, her yinelemede 2'şer asma kullanılacak şekilde Tesadüf Blokları Deneme desenine göre düzenlenmiş ve farklı grupların tespitinde LSD testinden faydalanılmıştır.

Proje alanında ana hastalıklar bağ küllemesi, bağ mildiyösü ve gerektiğinde ölü kol mücadelesinde koruma amaçlı kükürt ve bakır içerikli preparatlar kullanılmıştır. Ana zararlı salkım güvesine karşı ise gerektiğinde uygun insektisitlerden yararlanılmıştır. Ürünün kuş zararından korunması amacıyla, deneme alanına ben düşme zamanında dolu net çekilmiștir.

Denemede damla sulama sistemi uygulanmıştır. Sulamanın, A sınıfi buharlaşma kabından ölçülen buharlaşma değerlerinin \%50'si dikkate alınarak Tangolar ve ark. (2015 ve 2018)'na göre uygulanmasına dikkat edilmiştir. Her asma sırasında bir lateral kullanılmış ve lateral, gövdeye yakın pozisyonda geçirilmiş̧ir. Lateral olarak $20 \mathrm{~mm}$ dış çaplı ve 4 atm işletme basınçlı PE borular kullanılmıştır. Lateraller üzerinde, $50 \mathrm{~cm}$ aralıklarla bulunan damlatıcılar, içten geçik, kendinden basınç düzenleyicili ve $2-41 \mathrm{~h}^{-1}$ debili olarak düzenlenmiştir. Damla sulama sistemi $1.5 \mathrm{~kg} \mathrm{~cm}^{-2}(150 \mathrm{kPa})$ işletme basıncında çalıştırılmıştır. Sistemin kontrol biriminde motopomp, kumçakıl filtresi, mesh filtre, manometre, su sayac1, vanalar ve diğer gerekli parçalar yer almıştır.

\section{Bulgular ve Tartışma}

Verim bakımından kontrol her iki yılda da en düşük (sırasıyla $2604 \mathrm{~g} \mathrm{omca}^{-1}$ ve $1878 \mathrm{~g} \mathrm{omca}^{-1}$ ) değeri vermiştir. Kontrol uygulamasından birinci y1l $1734 \mathrm{~kg} \mathrm{da}^{-1}$, ikinci yıl 1250 $\mathrm{kg} \mathrm{da}^{-1}$ verim alınmıştır. Verim ve salkım ağırlığı bakımından, ilk yıl S+ÇG kompostu başarıliyken, ikinci y1l da pomza uygulamasının diğer uygulamalardan daha yüksek değerler verdiği saptanmıştır. S+ÇG kompostundan birinci yıl 2980 $\mathrm{kg} \mathrm{da}^{-1}$, ikinci yıl Pomza uygulamasından $2530 \mathrm{~kg} \mathrm{da}^{-1}$ verim alınmıştır. S+ÇG uygulaması kontrole göre birinci y1l 1246 $\mathrm{kg} \mathrm{da}^{-1}$, ikinci y1l Pomza uygulamasından $1280 \mathrm{~kg} \mathrm{da}^{-1}$ daha fazla ürün alınmıştır. Türkiye' de dekardan alınan üzüm verimi 865 kg'dır (TÜİK 2018). Bu çalışmada S+ÇG kompostu uygulaması ile, kontrole göre iki kat, Türkiye'deki dekara verim ortalamasının yaklaşı üç katı daha fazla üzüm verimi alınmıştır. Birinci yıl alınan ürün miktarının ikinci yıl bir miktar düşmesinin nedeninin ilkbahar döneminin yağışlı geçmesiyle bitkilerde bağ mildiyösü ve bağ küllemesi hastalığının yeterince iyi kontrol edilememesi olduğu düşünülmektedir. Salkımlar ilk y1l kontrol dahil bütün uygulamalarda orta büyüklükte (251-500 g); ikinci yıl $\mathrm{P}$ ve S+ÇG kompostu uygulamasında orta büyüklükte, diğerlerinde orta küçüklükte (126-250 g) salkım büyüklüğü grubuna girmiştir (Çelik 2011). Tane ağırlığı ve hacmi bakımından ilk yıl saman+çiftlik gübresi kompostu (sırasıyla $471.8 \mathrm{~g}$ ve $443.3 \mathrm{ml}$ ) ikinci yıl pomza+saman+çiftlik gübresi kompostu en yüksek değerleri (sırasıyla $368.2 \mathrm{~g}$ ve $346.7 \mathrm{ml}$ ) vermiştir (Çizelge 1). Bu değerlerin Çelik (2011)'e göre büyük taneli (3.5-4.4 g) üzümler grubu içine girdiği belirlenmiştir.

Uygulamaların şıra özellikleri üzerine etkisi yıllara göre farklılık göstermiştir. $\mathrm{P}+\mathrm{S}+\mathrm{C} G$ uygulamasında her iki yılda diğer uygulamalara göre daha yüksek SÇKM elde edilirken, ilk y1l yalnız pomza, 2. yıl kontrol uygulamasında daha düşük bulunmuştur. pH bakımından yapılan incelemede 2017 yılında $\mathrm{P}+\mathrm{KK}, \mathrm{P}+\mathrm{S}+\mathrm{C} G$ ve $\mathrm{S}+\mathrm{C} G ; 2018$ yılında ise $\mathrm{P}+$ Saman kompostunda daha yüksek değerler bulunmuştur. İlk yıl P+KK ile yalnız KK ve ardından $\mathrm{P}$ ve $\mathrm{P}+$ saman kompostunda; 2 . y1l kontrol ve $\mathrm{P}+$ saman kompostu ile KK uygulamasinda daha erken üzüm elde edilmiştir (Çizelge 2).

Çizelge 1. Early Sweet çeşidinde verim, salkım ve tane özellikleri üzerine farklı uygulamaların etkisi.

Table1. Effects of different treatments on yield, cluster and berry characteristics of Early Sweet variety.

\begin{tabular}{|c|c|c|c|c|c|c|c|c|}
\hline \multirow[t]{2}{*}{ Uygulamalar } & \multicolumn{2}{|c|}{$\begin{array}{c}\text { Verim } \\
\left(\mathrm{g} \text { omca }^{-1}\right)\end{array}$} & \multicolumn{2}{|c|}{$\begin{array}{c}\text { Salkım } \\
\text { Ağırlığı (g) }\end{array}$} & \multicolumn{2}{|c|}{$\begin{array}{l}\text { Tane ağırlı̆̆ } \\
\left(\mathrm{g} 100^{-1} \text { tane }\right)\end{array}$} & \multicolumn{2}{|c|}{ 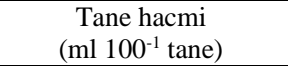 } \\
\hline & 2017 & 2018 & 2017 & 2018 & 2017 & 2018 & 2017 & 2018 \\
\hline Kontrol & $2604 d^{*}$ & $1878 \mathrm{c}$ & $260.4 \mathrm{~d}$ & $208.7 \mathrm{c}$ & $412.1 \mathrm{ab}$ & $315.0 \mathrm{bcd}$ & $383.3 \mathrm{ab}$ & $295.0 \mathrm{~cd}$ \\
\hline Pomza & $4009 \mathrm{abc}$ & 3799 a & $400.9 \mathrm{abc}$ & $422.1 \mathrm{a}$ & $434.1 \mathrm{ab}$ & $345.4 \mathrm{ab}$ & $410.0 \mathrm{ab}$ & $328.3 \mathrm{ab}$ \\
\hline KK & $3346 \mathrm{bcd}$ & $2003 c$ & $334.6 \mathrm{bcd}$ & $236.6 \mathrm{bc}$ & $437.8 \mathrm{ab}$ & $335.5 \mathrm{abc}$ & $410.0 \mathrm{ab}$ & $316.7 \mathrm{abc}$ \\
\hline $\mathrm{BA}+\mathrm{ÇG}$ & $3431 \mathrm{bcd}$ & $1886 \mathrm{c}$ & $343.1 \mathrm{bcd}$ & $209.5 \mathrm{c}$ & $421.3 \mathrm{ab}$ & $281.5 \mathrm{~d}$ & $393.3 \mathrm{ab}$ & $265.0 \mathrm{~d}$ \\
\hline $\mathrm{S}+\mathrm{ÇG}$ & $4474 \mathrm{a}$ & $2306 \mathrm{bc}$ & $447.4 \mathrm{a}$ & $256.3 \mathrm{bc}$ & $471.8 \mathrm{a}$ & $304.2 \mathrm{~cd}$ & $443.3 \mathrm{a}$ & $288.3 \mathrm{~cd}$ \\
\hline $\mathrm{P}+\mathrm{KK}$ & $3229 \mathrm{~cd}$ & $2216 \mathrm{bc}$ & $322.9 \mathrm{~cd}$ & $246.2 \mathrm{bc}$ & $406.8 \mathrm{ab}$ & $315.9 \mathrm{bcd}$ & $380.0 \mathrm{~b}$ & $298.3 \mathrm{bc}$ \\
\hline $\mathrm{P}+\mathrm{S}+\mathrm{C} G$ & $4231 \mathrm{ab}$ & $3411 \mathrm{ab}$ & $423.1 \mathrm{ab}$ & $379.0 \mathrm{ab}$ & $448.6 \mathrm{ab}$ & $368.2 \mathrm{a}$ & $420.0 \mathrm{ab}$ & $346.7 \mathrm{a}$ \\
\hline $\mathrm{P}+\mathrm{BA}+\mathrm{ÇG}$ & $3133 \mathrm{~cd}$ & $2220 \mathrm{bc}$ & $313.3 \mathrm{~cd}$ & $246.7 \mathrm{bc}$ & $387.7 \mathrm{~b}$ & $297.0 \mathrm{~d}$ & $370.0 \mathrm{~b}$ & $285.0 \mathrm{~cd}$ \\
\hline Ortalama & 3557 & 2465 & 355.7 & 275.6 & 427.5 & 320.3 & 401.2 & 302.9 \\
\hline LSD $\% 5$ & 927 & 1360 & 92.7 & 150.7 & 70.7 & 36.1 & 62.9 & 32.3 \\
\hline $\operatorname{Pr}>\mathrm{F}$ & 0.0091 & 0.0553 & 0.0091 & 0.0594 & 0.3312 & 0.0025 & 0.2962 & 0.0016 \\
\hline
\end{tabular}


Çizelge 2. Early Sweet çeşidinin şıra özellikleri üzerine farklı uygulamaların etkisi.

Table 2. Effects of different treatments on must characteristics of Early Sweet variety.

\begin{tabular}{|c|c|c|c|c|c|c|c|c|}
\hline \multirow{2}{*}{ Uygulamalar } & \multicolumn{2}{|c|}{ SÇKM (\%) } & \multicolumn{2}{|c|}{ Asitlik (\%) } & \multicolumn{2}{|c|}{$\mathrm{pH}$} & \multicolumn{2}{|c|}{ Olgunluk İndisi } \\
\hline & 2017 & 2018 & 2017 & 2018 & 2017 & 2018 & 2017 & 2018 \\
\hline Kontrol & $15.2 \mathrm{bc} *$ & $14.90 \mathrm{ab}$ & $0.764 \mathrm{a}$ & $0.705 \mathrm{c}$ & $3.33 \mathrm{~b}$ & $3.32 \mathrm{c}$ & $19.9 \mathrm{bc}$ & $21.31 \mathrm{a}$ \\
\hline Pomza & $15.6 \mathrm{abc}$ & $14.77 \mathrm{ab}$ & $0.659 \mathrm{~b}$ & $0.855 \mathrm{bc}$ & $3.43 \mathrm{ab}$ & $3.39 \mathrm{bc}$ & $23.7 \mathrm{abc}$ & $17.46 \mathrm{abc}$ \\
\hline KK & $16.3 \mathrm{ab}$ & $14.89 \mathrm{ab}$ & $0.673 \mathrm{ab}$ & $0.774 \mathrm{bc}$ & $3.40 \mathrm{ab}$ & $3.36 \mathrm{bc}$ & $24.4 \mathrm{ab}$ & $19.39 \mathrm{ab}$ \\
\hline $\mathrm{BA}+\mathrm{ÇG}$ & $15.4 \mathrm{abc}$ & $14.30 \mathrm{ab}$ & $0.755 \mathrm{ab}$ & $0.772 \mathrm{bc}$ & $3.42 \mathrm{ab}$ & $3.45 \mathrm{~b}$ & $20.4 \mathrm{abc}$ & $18.60 \mathrm{abc}$ \\
\hline $\mathrm{S}+\mathrm{ÇG}$ & $16.0 \mathrm{abc}$ & $14.03 \mathrm{abc}$ & $0.686 \mathrm{ab}$ & $1.011 \mathrm{a}$ & $3.50 \mathrm{a}$ & $3.39 \mathrm{bc}$ & $23.3 \mathrm{abc}$ & $14.00 \mathrm{c}$ \\
\hline $\mathrm{P}+\mathrm{KK}$ & $16.5 \mathrm{ab}$ & $13.47 \mathrm{bc}$ & $0.668 \mathrm{ab}$ & $0.856 \mathrm{abc}$ & $3.46 \mathrm{a}$ & $3.32 \mathrm{c}$ & $25.1 \mathrm{a}$ & $15.74 \mathrm{c}$ \\
\hline $\mathrm{P}+\mathrm{S}+\mathrm{ÇG}$ & $16.8 \mathrm{a}$ & $15.80 \mathrm{a}$ & $0.713 a b$ & $0.818 \mathrm{bc}$ & $3.49 \mathrm{a}$ & $3.63 \mathrm{a}$ & $23.8 \mathrm{abc}$ & $19.97 \mathrm{ab}$ \\
\hline $\mathrm{P}+\mathrm{BA}+\mathrm{C} G$ & $14.5 \mathrm{c}$ & $12.21 \mathrm{c}$ & $0.769 \mathrm{a}$ & $0.918 \mathrm{ab}$ & $3.40 \mathrm{ab}$ & $3.31 \mathrm{c}$ & $19.0 \mathrm{bc}$ & $13.46 \mathrm{c}$ \\
\hline Ortalama & 15.8 & 14.30 & 0.711 & 0.839 & 3.43 & 3.40 & 22.5 & 17.49 \\
\hline LSD \% 5 & 1.6 & 2.0 & 0.102 & 0.153 & 0.11 & 0.10 & 4.9 & 5.28 \\
\hline $\operatorname{Pr}>\mathrm{F}$ & 0.1148 & 0.0476 & 0.1572 & 0.0183 & 0.0710 & 0.0001 & 0.1191 & 0.0510 \\
\hline
\end{tabular}

BA+ÇG, Saman+Çiftlik Gübresi: S+ÇG, Pomza+Kuru Kompost: P+KK, Pomza+Saman+Çiftlik Gübresi: P+S+ÇG, Pomza+Budama artı̆ı+Çiftlik Gübresi:P+BA+ÇG.

Bitkilerin azot içeriği bakımından BA ve saman kompostu ile bunların pomza ile kombinasyonundan her iki yılda daha yüksek değerler elde edilmiştir. Fosfor bakımından 1. yıl yalnız pomza; 2. y1l ise pomza +kuru kompost ve pomza + saman kompostu iyi sonuç vermiştir. Potasyum içeriği her iki yılda pomza uygulamasında daha yüksek çıkmış; Yaprakların $\mathrm{Ca}$ içeriği 1. yıl pomza+saman malçı, 2. yıl saman malçı ve kontrol uygulamasında yüksek çıkmıştır. Mg bakımından 1. yıl yalnız budama artığı kompost uygulama değeri yüksek çıkmış, 2. yıl kontrol ve saman malçı ile pomza+budama artığı kompostu aynı değerle ilk grupta yer almıştır (Çizelge 3).

$\mathrm{Fe}$ değerleri genel olarak $\mathrm{BA}+\mathrm{C} G$ ve $\mathrm{P}$ ile $\mathrm{P}+$ saman kompostu ve $\mathrm{P}+$ budama artığı kompostunda daha yüksek çıkmıştır. Manganda da genel olarak P+kompost uygulamalarında değerlerin daha yüksek olduğu görülmüştür. Bütün uygulamalarda değerlerin noksanlık sınırı içinde yer aldığ $;$ Zn bakımından ise denemenin 1. yılında pomza ilaveli ve ilavesiz budama artığı kompostu ile 2. yılda pomza ilaveli Budama artığı kompostu ve saman kompostu ile kontrol uygulamasının en yüksek değerleri aldığı belirlenmiştir (Çizelge 4). Yapılan analizler sonucunda bu aşamada genel olarak bakıldığında makro ve mikro besin maddelerinden uygulamalar ve yıllara göre belirgin olarak üstünlük gösteren olmamakla beraber, tüm uygulamalarda deneme alanında Jones ve ark. (1991)'na göre N, Fe ve Mn'ın fazla, P'un yeterli, Ca'un yeterli-noksan, $\mathrm{K}, \mathrm{Mg}$ ve $\mathrm{Zn}$ 'nun noksan düzeyinde olduğu belirlenmiştir.

Kompostların yalnız veya Pomza ile karışım halinde birikimli etkisinin gözlenmesi amacıyla çalışmalara devam edilmesinde yarar görülmektedir. Cabilovski ve ark. (2014)' nın çalışmasında kompostun kalıcı etkisinin daha uzun sürdüğü, sonbaharda uygulanan kompostlaştırılmış gübreden organik $\mathrm{N}^{\prime}$ un yalnızca \%11'inin ve kompostlaştırılmamış gübreden ise $\% 21$ 'inin ertesi yıl mineralize olduğu ileri sürülmüştür.

Çizelge 3. Early Sweet çeşidinde tam çiçekleme döneminde alınan yaprak örneklerinde bulunan makro element içerikleri (\%).

Table 3. Macro element contents in leaf samples taken from Early Sweet variety in full flowering time (\%).

\begin{tabular}{|c|c|c|c|c|c|c|c|c|c|c|c|}
\hline \multirow{2}{*}{\multicolumn{2}{|c|}{ Uygulamalar }} & \multicolumn{2}{|c|}{$\mathrm{N}$} & \multicolumn{2}{|c|}{$\mathrm{P}$} & \multicolumn{2}{|c|}{$\mathrm{K}$} & \multicolumn{2}{|c|}{$\mathrm{Ca}$} & \multicolumn{2}{|c|}{$\mathrm{Mg}$} \\
\hline & & 2017 & 2018 & 2017 & 2018 & 2017 & 2018 & 2017 & 2018 & 2017 & 2018 \\
\hline \multicolumn{2}{|l|}{ Kontrol } & $3.32 \mathrm{bc}^{*}$ & $3.01 \mathrm{ab}$ & $0.26 \mathrm{ab}$ & $0.38 \mathrm{ab}$ & $0.50 \mathrm{bc}$ & $0.55 \mathrm{ab}$ & $1.06 \mathrm{bc}$ & $1.48 \mathrm{a}$ & $0.13 \mathrm{c}$ & $0.19 \mathrm{a}$ \\
\hline \multicolumn{2}{|l|}{ Pomza } & $3.13 \mathrm{c}$ & $3.07 \mathrm{ab}$ & $0.29 \mathrm{a}$ & $0.48 \mathrm{a}$ & $0.80 \mathrm{a}$ & $0.70 \mathrm{a}$ & $0.93 \mathrm{c}$ & $0.84 \mathrm{~b}$ & $0.09 \mathrm{~d}$ & $0.10 \mathrm{c}$ \\
\hline \multicolumn{2}{|l|}{$\mathrm{KK}$} & $3.46 \mathrm{ab}$ & $2.72 \mathrm{~b}$ & $0.23 \mathrm{c}$ & $0.42 \mathrm{ab}$ & $0.59 \mathrm{abc}$ & $0.55 \mathrm{ab}$ & $1.12 \mathrm{abc}$ & $0.97 \mathrm{~b}$ & $0.14 \mathrm{abc}$ & $\begin{array}{c}0.13 \\
\mathrm{bc}\end{array}$ \\
\hline \multicolumn{2}{|l|}{$\mathrm{BA}+\mathrm{ÇG}$} & $3.55 \mathrm{a}$ & $3.31 \mathrm{ab}$ & $0.22 \mathrm{bc}$ & $0.27 \mathrm{~b}$ & $0.60 \mathrm{abc}$ & $0.44 \mathrm{~b}$ & $1.37 \mathrm{ab}$ & $1.27 \mathrm{ab}$ & $0.18 \mathrm{a}$ & $\begin{array}{c}0.16 \\
\mathrm{ab}\end{array}$ \\
\hline \multicolumn{2}{|l|}{$\mathrm{S}+\mathrm{ÇG}$} & $3.50 \mathrm{ab}$ & $3.69 \mathrm{a}$ & $0.21 \mathrm{bc}$ & $0.26 \mathrm{~b}$ & $0.60 \mathrm{abc}$ & $0.42 \mathrm{~b}$ & $1.04 \mathrm{c}$ & $1.42 \mathrm{a}$ & $0.17 \mathrm{ab}$ & $0.19 \mathrm{a}$ \\
\hline \multicolumn{2}{|l|}{$\mathrm{P}+\mathrm{KK}$} & $3.34 \mathrm{abc}$ & $3.58 \mathrm{a}$ & $0.24 \mathrm{bc}$ & $0.49 \mathrm{a}$ & $0.66 \mathrm{abc}$ & $0.52 \mathrm{ab}$ & $1.20 \mathrm{abc}$ & $0.97 \mathrm{~b}$ & $0.15 \mathrm{abc}$ & $\begin{array}{c}0.16 \\
a b\end{array}$ \\
\hline \multicolumn{2}{|l|}{$\mathrm{P}+\mathrm{S}+\mathrm{C} G$} & $3.44 \mathrm{ab}$ & $3.69 \mathrm{a}$ & $0.21 \mathrm{c}$ & $0.50 \mathrm{a}$ & $0.66 \mathrm{ab}$ & $0.45 \mathrm{~b}$ & $1.42 \mathrm{a}$ & $1.24 \mathrm{ab}$ & $0.14 b c$ & $\begin{array}{c}0.15 \\
\mathrm{ab}\end{array}$ \\
\hline \multicolumn{2}{|c|}{$\mathrm{P}+\mathrm{BA}+\mathrm{C} G$} & $3.42 \mathrm{ab}$ & $3.72 \mathrm{a}$ & $0.23 \mathrm{bc}$ & $0.43 \mathrm{ab}$ & $0.45 \mathrm{c}$ & $0.52 \mathrm{ab}$ & $1.14 \mathrm{abc}$ & $1.22 \mathrm{ab}$ & $0.16 \mathrm{abc}$ & $0.19 \mathrm{a}$ \\
\hline \multicolumn{2}{|c|}{ Ortalama } & 3.40 & 3.35 & 0.23 & 0.40 & 0.61 & 0.52 & 1.16 & 1.18 & 0.15 & 0.16 \\
\hline \multicolumn{2}{|l|}{ LSD $\% 5$} & 0.28 & 0.80 & 0.05 & 0.20 & 0.21 & 0.22 & 0.31 & 0.43 & 0.04 & 0.04 \\
\hline \multicolumn{2}{|l|}{ P değeri } & 0.0295 & 0.1128 & 0.0316 & 0.1090 & 0.0808 & 0.2230 & 0.0623 & 0.0675 & 0.0040 & 0.0019 \\
\hline \multirow{3}{*}{$\begin{array}{l}\text { Sınır } \\
\text { Değerler }\end{array}$} & Noksan & \multicolumn{2}{|c|}{$<1.70$} & \multicolumn{2}{|c|}{$<0.15$} & \multicolumn{2}{|c|}{$<1.50$} & \multicolumn{2}{|c|}{$<1.00$} & \multicolumn{2}{|c|}{$<0.30$} \\
\hline & Yeterli & \multicolumn{2}{|c|}{$1.70-3.0$} & \multicolumn{2}{|c|}{$0.15-0.50$} & \multicolumn{2}{|c|}{$1.50-2.00$} & \multicolumn{2}{|c|}{$1.00-3.00$} & \multicolumn{2}{|c|}{$0.30-1.50$} \\
\hline & Fazla & \multicolumn{2}{|c|}{$>3.0$} & \multicolumn{2}{|c|}{$>0.50$} & \multicolumn{2}{|c|}{$>2.00$} & \multicolumn{2}{|c|}{$>3.00$} & \multicolumn{2}{|c|}{$>1.50$} \\
\hline
\end{tabular}

*: Aynı sütun içerisinde farklı harflerle gösterilen ortalamalar arasında istatistiki farklılık bulunmaktadır $\mathrm{P} \leq 0.05$. Kuru Kompost: KK, Budama artığı+Ciflik Gübresi: BA+ÇG, Saman+Çiftlik Gübresi: S+ÇG, Pomza+Kuru Kompost: P+KK, Pomza+Saman+Çiftlik Gübresi: P+S+ÇG, Pomza+Budama artığı+Çiftlik Gübresi:P+BA+ÇG. 
Çizelge 4. Early Sweet çeşidinde tam çiçeklenme döneminde alınan yaprak örneklerinde bulunan mikro element içerikleri (mg kg-1). Table 4. Micro element contents in leaf samples taken from Early Sweet variety in full flowering time $\left(\mathrm{mg} \mathrm{kg}^{-1}\right)$.

\begin{tabular}{|c|c|c|c|c|c|c|c|}
\hline \multirow{2}{*}{ bUygulamalar } & & \multicolumn{2}{|c|}{$\mathrm{Fe}$} & \multicolumn{2}{|c|}{$\mathrm{Mn}$} & \multicolumn{2}{|c|}{$\mathrm{Zn}$} \\
\hline & & 2017 & 2018 & 2017 & 2018 & 2017 & 2018 \\
\hline Kontrol & & $83.2 \mathrm{c} *$ & 57.7 bcd & $82.6 \mathrm{bc}$ & $63.4 \mathrm{abc}$ & $16.9 \mathrm{~b}$ & $14.9 \mathrm{a}$ \\
\hline Pomza & & $106.3 \mathrm{ab}$ & $74.0 \mathrm{ab}$ & $79.5 \mathrm{bcd}$ & $52.8 \mathrm{c}$ & $17.1 \mathrm{~b}$ & $11.0 \mathrm{c}$ \\
\hline KK & & $84.3 \mathrm{c}$ & $45.6 \mathrm{~d}$ & $60.8 \mathrm{~d}$ & $61.5 \mathrm{abc}$ & $17.3 \mathrm{~b}$ & $14.5 a b$ \\
\hline $\mathrm{BA}+\mathrm{ÇG}$ & & $110.5 \mathrm{a}$ & $70.8 \mathrm{abc}$ & $98.1 \mathrm{ab}$ & $48.8 \mathrm{c}$ & $22.8 \mathrm{a}$ & $13.4 \mathrm{abc}$ \\
\hline $\mathrm{S}+\mathrm{ÇG}$ & & $91.5 \mathrm{c}$ & $60.7 \mathrm{abcd}$ & $82.10 \mathrm{bc}$ & $48.1 \mathrm{c}$ & $17.2 \mathrm{~b}$ & $15.2 \mathrm{a}$ \\
\hline $\mathrm{P}+\mathrm{KK}$ & & $83.0 \mathrm{c}$ & $53.9 \mathrm{~cd}$ & $73.8 \mathrm{~cd}$ & $74.4 \mathrm{ab}$ & $16.6 \mathrm{~b}$ & $14.6 \mathrm{ab}$ \\
\hline $\mathrm{P}+\mathrm{S}+\mathrm{ÇG}$ & & $112.4 \mathrm{a}$ & $78.1 \mathrm{a}$ & $91.8 \mathrm{bc}$ & $53.1 \mathrm{bc}$ & $17.5 \mathrm{~b}$ & $11.8 \mathrm{bc}$ \\
\hline $\mathrm{P}+\mathrm{BA}+\mathrm{C} G$ & & $93.2 \mathrm{bc}$ & $70.4 \mathrm{abc}$ & $113.31 \mathrm{a}$ & $75.2 \mathrm{a}$ & $18.4 \mathrm{ab}$ & $15.3 \mathrm{a}$ \\
\hline Ortalama & & 95.53 & 63.9 & 85.27 & 59.66 & 17.98 & 13.84 \\
\hline LSD \%5 & & 13.3 & 19.8 & 18.9 & 21.5 & 4.53 & 2.8 \\
\hline P değeri & & 0.003 & 0.0376 & 0.0011 & 0.0830 & 0.1586 & 0.0283 \\
\hline \multirow{3}{*}{$\begin{array}{l}\text { Sınır } \\
\text { Değerler }\end{array}$} & Noksan & \multicolumn{2}{|c|}{$<40$} & \multicolumn{2}{|c|}{$<30$} & \multicolumn{2}{|c|}{$<25$} \\
\hline & Yeterli & \multicolumn{2}{|c|}{$40-300$} & \multicolumn{2}{|c|}{$30-150$} & \multicolumn{2}{|c|}{$25-100$} \\
\hline & Fazla & \multicolumn{2}{|c|}{$>300$} & \multicolumn{2}{|c|}{$>150$} & \multicolumn{2}{|c|}{$>100$} \\
\hline
\end{tabular}

*: Aynı sütun içerisinde farklı harflerle gösterilen ortalamalar arasında istatistiki farklılık bulunmaktadır P $\leq 0.05$. Kuru Kompost: KK, Budama artığı+Ciflik Gübresi: BA+ÇG, Saman+Çiftlik Gübresi: S+ÇG, Pomza+Kuru Kompost: P+KK, Pomza+Saman+Çiftlik Gübresi: P+S+ÇG, Pomza+Budama artığı+Çiftlik Gübresi:P+BA+ÇG.

\section{Sonuç}

Çalışma sonunda belirtilen miktarlarda saman ve budama artığı kompostu ile ilaveten pomza uygulamasının bazı özelliklerde olumlu etkileri görülmüştür. Bu uygulamalardan Türkiye ortalamasının üzerinde ve dekardan yaklaşık 2.5- 3.0 ton üzüm elde edilmiştir. Salkım, tane ve şıra özellikleri bakımından uygulamalar arasındaki farklılıklar yıllara göre çok belirgin çıkmamıştır.

Besin maddesi analiz sonuçlarının değerlendirmesinden deneme alanında tüm uygulamalarda $\mathrm{N}, \mathrm{Fe}$ ve Mn' in fazla, $\mathrm{P}$ un yeterli, Ca'un yeterli-noksan, $\mathrm{K}, \mathrm{Mg}$ ve $\mathrm{Zn}$ ' nun noksan düzeyinde olduğu değerlendirilmiştir.

Kompostların yalnız veya Pomza ile karışım halinde birikimli etkisinin gözlenmesi amacıyla çalışmalara devam edilmesinde yarar görülmektedir.

\section{Teşekkür}

Bu çalışma, Çukurova Üniversitesi Bilimsel Araştırma Projeleri Koordinasyon Birimi tarafindan (Proje No: FBA2017-7402) desteklenmiştir.

\section{Kaynaklar}

Aggelides SM, Londra PA (2000) Effects of compost produced from town wastes and ewage sludge on the physical properties of a loamy and a clay soil. Bioresour. Technol. 71: 253-259.

Altieri MA (1987) Agroecology. Westview Press (Boulder). IT Publications, London. pp. 227.

Anaç D, Okur B, Akdeniz RC, Gülsoylu E, Atilla A (2002) Organik Tarımda Toprak Verimliliği, Organik Tarım, Organik (Ekolojik) Tarım Eğitimi Ders Notları, Emre Basımevi, İzmir, s. 79-147.

Bayraklı F, Er F (1998) Hadim Aladağ bölgesindeki üzüm bağlarının azot, fosfor, potasyum, kalsiyum ve magnezyum düzeylerinin belirlenmesi üzerine bir araştırma. 4. Bağcılık Sempozyumu, Yalova.

Bhangoo MS, Day KS, Sudanagunta VR, Petrucci VE (1988) Application of paultry manure influences Thompson Seedless grape production and soil properties. Hort Science 23(6): 1010-1012.
Cabilovski R, Manojlovic1 M, Bogdanovic1 D, Magazin1 N, Keserovic1 Z, Sitaula BK (2014) Mulch type and application of manure and composts in strawberry (Fragaria $\times$ ananassa Duch.) production: impact on soil fertility and yield. ZemdirbysteAgriculture 101, 1: 67-74.

Curtis MJ, Claassen VP (2005) Compost incorporation increases plant available water in a drastically disturbed serpentine soil. Soil Sci. 170: 939-953.

Curtis MJ, Claassen VP (2009) Regenerating topsoil functionality in four drastically disturbed soil types by compost incorporation. Restor. Ecol. 17: 24-32.

Çelik S (2011) Bağcılık (Ampeloloji).Dağıtım, Namık Kemal Üniv. Ziraat Fak. Bahçe Bitkileri Böl. Tekirdağ, (1): 428.

Çelik H, Ağaoğlu S, Fidan Y, Marasalı B, Söylemezoğlu G (1998) Genel Bağcilık. Sunfidan A. Ş. Mesleki Kitaplar Serisi: 1. Fersa Matbacılık San. Tic. Ltd. Şti. Kızılay- Ankara.

Çelik H, Çelik S, Marasalı Kunter B, Söylemezoğlu G, Boz Y, Özer C, Atak A (2005) Bağcılıkta gelişme ve üretim hedefleri. VI. Türkiye Ziraat Mühendisliği Teknik Kongresi, Ankara, s. 22.

Ecevit FM (1980) Bazı Amerikan asma anaçlarının Yuvarlak Çekirdeksiz üzüm çeşidinin mineral beslenmesi, vegetatif gelişmesi ve meyve özelliklerine etkileri üzerinde araştırmalar, Doçentlik Tezi, Bornova- İzmir.

Ecevit FM (1986) R 99 Amerikan asma anacı üzerine aşılı bazı üzüm çeşitlerinde mineral besin maddeleri arasındaki ilişkiler üzerinde araştırmalar. Selçuk Üniv. Yay: 22, Ziraat Fak. Yay: 3. Konya.

Jamroz E, Drozd J (1999) Influence of applying compost from municipal wastes on some physical properties of the soil. International Agrophysics 13: 167-170.

Jones JB, Wolf Jr B, Mills HA (1991) Plant analysis handbook. I. methods of plant analysis and interpratation. Micro-Macro Publishing Inc.,183 Paradise Blvd, Suite 108, Athens Georgia 30607, USA.

Kaçar B (1972) Bitki ve toprağın kimyasal analizleri: II, bitki analizleri. Ankara Üniversitesi Ziraat Fakültesi Yayınları: 453, Uygulama Kilavuzu:155, Ankara.

Kaçar B (1995) Toprak analizleri. Bitki ve toprağın kimyasal analizleri: III. Ankara Üniversitesi Ziraat Fakültesi Eğitim Araştırma ve Geliştirme Vakfı Yayınları, No: 3, Ankara, s. 705. 
Korboulewsky N, Robles C, Garzino S (2004) Efects of sewage sludge compost on volatile organic compounds of wine from Vitis vinifera cv. Red Grenache. Am. J. Enol. Viticult. 55: 412-416.

Lampkin N (1990) Organic farming. Farming Press Books. U.K. pp. 701.

Mylavarapu RS, Zinati GM (2009) Improvement of soil properties using compost for optimum parsley production in sandy soils. Sci. Hortic. 120: 426-430.

Pinamonti F (1998) Compost mulch effects on soil fertility, nutritional status and performance of grapevine. Nutr. Cycling Agroecosyst 51: 239-248.

Pool RM, Dunst RM, Lakso AN (1990) Comparison of sod, mulch, cultivation, and herbicide floor management practices for grape production in non irrigated vineyards. J. Amer. Soc. Hort. Sci. 115(6): 872-877.

Porro D, Stefanini M, Failla O, Stringari G (1996) Optimal leaf sampling time in diagnosis of grapevine nutritional status. Hort. Abstr. 66(4): 3042.

Powell KS, Burns A, Norng S, Granett J, McGourty G (2007) Influence of composted green waste on the population dynamics and dispersal of grapevine phylloxera Daktulosphaira vitifoliae. Agri. Ecosyst. and Environ. 119: 33-38.

Rodeghiero M, Rubio A, Díaz-Pinés E, Romanyà J, MarañónJiménez S, Levy GJ, Fernandez-Getino AP, Sebastià MT, Karyotis T, Chiti T, Sirca C, Martins A, Madeira M, Zhiyanski M, Gristina L, La Mantia T (2011) Soil carbon in Mediterranean ecosystems and related management problems, in: Jandl R, Rodeghiero M, Olsson
M (Ed), Soil Carbon in Sensitive European Ecosystems. John Wiley \& Sons, Chichester, s. 175-218.

Sodhi GPS, Beri V, Benbi DK (2009) Soil aggregation and distribution of carbon and nitrogen in different fractions under long-term application of compost in rice-wheat system. Soil and Till. Res. 103: 412-418.

Tangolar S, Ergenoğlu F (1989) Değişik anaçların erkenci bazı üzüm çeşitlerinde yaprakların mineral besin maddesi ve çubukların karbonhidrat içerikleri üzerine etkisi. Doğa, Türk Tar. ve Orm. Dergisi 13(3b): 1267-1283.

Tangolar S, Tangolar S, Tarım G, Ada M (2018) Pozantı koşullarında yetiştirilen Semillon ve Carignane üzüm çeşitlerinde kısıntılı sulamanın verim, kalite ve taç gelişimi üzerine etkilerinin belirlenmesi. YYÜ Tar. Bil. Derg. 28(1): 92-102.

Tangolar S, Tangolar S, Topçu S (2015) Effects of different bud loads and irrigations applied at different leaf water potential levels on Kalecik Karası grape variety. Turk J Agric For. 39: 887-897.

TÜİK, 2018. Türkiye İstatistik Kurumu. Erişim 26 Haziran 2018.

Weaver RJ (1976) Grape Growing. A Wiley Inter science Pub. s. 371.

Winkler AJ, Cook JA, Kliewer WM, Lider LA (1974) General Viticulture. Univ. of California Press, Berkeley. s. 710.

Yılmaz N (1993) Yuvarlak çekirdeksiz üzüm bağlarında farklı derinlik ve mesafelerde uygulanan kompoze bübrenin beslenme üzerine etkisi. T. C. Tarım ve Köy İşleri Bakanlığı, Yayın No: 51. Bağcılık Araştırma Entitüsü Müdürlüğü. Manisa. s. 25. 